\title{
Análise comparativa de ferramentas de gestão de portfólio: um estudo de caso na indústria alimentícia
}

\author{
Carla Pedroso ${ }^{\mathrm{a} *}$, Istefani Carísio de Paula ${ }^{\mathrm{b}}$, Joana Siqueira de Souza ${ }^{\mathrm{c}}$ \\ a*pedrosocs@yahoo.com.br, UFRGS, Brasil \\ bistefani@producao.ufrgs.br, UFRGS, Brasil \\ cjoana.souza@pucrs.br, PUCRS, Brasil
}

\begin{abstract}
Resumo
A gestão de portfólio (GP) é uma importante atividade dentro do processo de desenvolvimento de produtos. Ela envolve a tomada de decisão sobre os produtos da empresa, a qual reflete, em última análise, as decisões do negócio. Existem na literatura diferentes modelos e ferramentas que podem ser usados na GP. No presente trabalho são avaliados os resultados da aplicação de duas ferramentas de GP, uma que se fundamenta no modelo de pontuação (scoring model) e outra fundamentada no modelo econômico-financeiro. 0 estudo foi realizado em uma empresa de pequeno porte do setor alimentício onde a aplicabilidade dessas ferramentas foi analisada. Os resultados indicaram que as duas ferramentas estudadas podem ser empregadas de forma complementar e revelaram que embora elas utilizem fundamentos distintos, geraram portfólios compatíveis.
\end{abstract}

Palavras-chave

Gestão de portfólio. Modelo de pontuação. Modelo econômico-financeiro.

\section{Introdução}

A qualidade do processo de desenvolvimento de produtos (PDP) tem forte influência sobre o sucesso dos negócios de organizações que trabalham com manufatura, determinando a competitividade delas no mercado. A gestão do PDP consiste em direcionar os esforços de produção para as necessidades do mercado e o emprego de novas tecnologias existentes, possibilitando atrair e manter os consumidores (ROZENFELD et al., 2006; SLACK; CHAMBERS; JOHNSTON, 2002; CRAWFORD; BENEDETTO, 2000; PATTERSON; FENOGLIO, 1999).

As transações comerciais, a troca de informações entre os países e a fácil difusão de informação pelos meios de comunicação permitem aos consumidores ter acesso a diferentes tipos de produtos, inclusive alimentícios, de uma maneira mais fácil, levando a busca por produtos novos e, ao mesmo tempo, de qualidade. Tal fato tem levado as empresas à criação de novos produtos que atendam tanto às necessidades dos clientes quanto aos objetivos e estratégias da empresa, enfatizando a gestão do portfólio de produtos, o seu balanceamento e revisão constante (KERZNER, 2006; PROJECT..., 2006; DANILEVICZ, 2006).

Nas empresas alimentícias nacionais, essa é uma realidade enfrentada até mesmo porque alimentos são commodity e têm ciclo de vida relativamente curto, variando de um a dois anos, dependendo do produto. Essas empresas precisam tanto atender às exigências dos clientes com novos hábitos de consumo quanto ser competitivas perante seus concorrentes, tendo que oferecer produtos com preços atraentes, atender às legislações específicas que regem o setor alimentício, sendo inspecionadas pelos órgãos sanitários nacionais competentes (BRASIL, 2002). Os administradores de tais empresas devem, deste modo, lançar um olhar cuidadoso sobre o PDP e a GP e atender dois requisitos desafiantes: fazer uso do menor número de recursos e desenvolver novos produtos no menor espaço de tempo possível. Lidar com esses desafios exige que 
exista nas empresas um PDP estruturado e eficiente, principalmente no que diz respeito à GP.

Segundo Cooper, Edgett e Kleinschmidt (2001), a GP pode ser definida como a maneira mais eficiente de priorizar os projetos e tomar decisões estratégicas dentro de uma organização. A formalização da decisão gerencial durante o desenvolvimento de produto é recomendada na literatura, porém percebe-se que, na prática, as empresas tomam as decisões sobre projetos de desenvolvimento com base em poucos testes ou poucas opiniões (ROZENFELD et al., 2006). A utilização de ferramentas de GP, sistematizando o processo de tomada de decisão e a priorização de projetos, pode ajudar a minimizar essa deficiência em empresas de diferentes portes.

Existem alguns trabalhos relacionados ao PDP e à gestão de portfólio (GP) na indústria alimentícia, tais como os de Bosi (2003), Monteiro (2003) e Mizuta (2000), que convergem para a idéia de que o setor depende muito da tecnologia de processo. Entretanto, grande parte das empresas nacionais compete pelo mercado de baixo e médio poder aquisitivos, de tal forma que essas empresas buscam soluções simples que, impactando no seu portfólio, enfatizem a redução de custos (BOSI, 2003).

0 mercado de alimentos propicia real competição entre as empresas. Esse cenário leva à necessidade de diferenciação e investimentos capazes de estimular a percepção dos consumidores. Dados atuais da Associação Brasileira das Indústrias da Alimentação (ASSOCIAÇÃO..., 2008) mostram que a indústria de alimentos faturou R\$230,6 bilhões em 2007, uma alta de 10,6\% em relação ao ano anterior. A perspectiva para o corrente ano é de que a produção continue crescendo.

De acordo com Lourenzani (2002), existe uma lacuna entre a teoria e a prática da GP. Na indústria alimentícia, a falta de estruturação do PDP e a falta de reconhecimento da importância do gerenciamento do portfólio podem ser citadas como as principais barreiras para a implantação de uma sistemática de GP.

Em virtude da importância da GP como norteador do processo de tomada de decisão e do impacto dessa gestão no sucesso do negócio, o objetivo geral deste trabalho consiste na comparação de duas ferramentas de análise de portfólio, aplicadas em uma empresa de pequeno porte. 0 objetivo é verificar a adequabilidade das ferramentas, vantagens e desvantagens em relação ao caso estudado. Os objetivos específicos são: (i) realizar uma análise crítica em relação à aplicabilidade de cada ferramenta, assim como de seus critérios, para o setor alimentício; (ii) avaliar se o resultado obtido é coerente com a realidade da empresa; e (iii) avaliar a satisfação da gerência quanto aos resultados obtidos com o uso das ferramentas.

Para alcançar os objetivos apresentados na primeira seção, o artigo foi organizado em quatro partes. $\mathrm{Na}$ primeira estão apresentados alguns conceitos teóricos que devem auxiliar no entendimento do estudo a respeito de GP de produtos e projetos e a respeito de ferramentas utilizadas para a GP. Em seguida é apresentada uma análise comparativa das ferramentas escolhidas para este estudo de caso. A segunda parte apresenta a metodologia de pesquisa e de trabalho. Os dados da situação atual e os resultados da aplicação das ferramentas são mostrados e discutidos na terceira parte do artigo. Por fim são apresentadas, na quarta parte, as conclusões acerca da pesquisa realizada.

\section{Fundamentação teórica}

De acordo com Cooper, Edgett e Kleinschmidt (2001), a GP de produtos é um processo de decisão dinâmico através do qual a lista de novos produtos ativos do negócio e dos projetos de P\&D é revisada periodicamente. Com isso, os projetos são avaliados e priorizados, podendo ser acelerados, abortados ou alterados. 0 gerenciamento de portfólio de produtos tem como um de seus objetivos servir ao acompanhamento do ciclo de vida dos produtos da empresa a fim de otimizar a alocação de recursos. Além disso, também visa (1) maximizar o valor dos produtos do portfólio, assegurando um balanceamento entre os diferentes tipos de produto; (2) criar projetos que visem gerar novos produtos, permitindo alocar e realocar recursos; (3) permitir o alinhamento estratégico das decisões de desenvolvimento de produtos com os objetivos e as estratégias da empresa (COOPER; EDGETT; KLEINSCHMIDT, 2001). Ainda segundo esses autores, existem consequências imediatas e não imediatas para a empresa que não possui um método para a GP, como, por exemplo, um número muito grande de projetos em andamento e muitas falhas de lançamento, respectivamente.

De acordo com o Project Management Institute - PMI (PROJECT..., 2004, 2006), o controle do portfólio está relacionado aos objetivos específicos da empresa e a gestão do portfólio pode ser definida como a prática de identificar, selecionar e gerenciar projetos e programas que contribuam para alavancar o negócio.

0 contexto atual requer das empresas uma melhor capacitação. Particularmente, é necessária uma melhor compreensão do papel estratégico do PDP, isto é, uma visão mais ampla desse processo, desde a definição inicial da estratégia do produto até as etapas de retirada do mesmo do mercado (ROZENFELD et al., 2006; CRAWFORD; BENEDETO, 
2000; PATTERSON; FENOGLIO, 1999). Além disso é necessária capacitação para desenvolver produtos que atendam às expectativas dos clientes e consumidores finais, que sejam viáveis de serem produzidos e que estejam alinhados com as estratégias competitivas da empresa. Em resumo, a "manobrabilidade" para desenvolver as características do produto levará a empresa à diferenciação competitiva (KOTLER, 1998).

Em um ambiente competitivo como o mercado de alimentos, e num segmento de recursos limitados, como o das pequenas empresas, torna-se indispensável a aplicação adequada dos recursos, transformando-se esta um fator decisivo para sua sobrevivência (SOUZA, 2008). Nesse cenário, a adequada GP é necessária para que somente os projetos de produtos que terão aceitação no mercado e que trarão retorno financeiro sejam levados adiante.

Então, como tomar a decisão mais correta com relação à GP? Uma forma de tomar decisões objetivas e científicas, com relação à GP, é por meio do uso de ferramentas. Os objetivos do uso de uma ferramenta são simplificar o processo de GP, trazer formalismo para as etapas realizadas informalmente e criar um mecanismo de ajuste da GP à cultura da empresa (DUTRA, 2007).

\subsection{Ferramentas e modelos de gestão de portfólio}

Os diversos modelos de GP convergem para o objetivo único de guiar a seleção de projetos e reafirmam a complexidade desse processo. Os modelos de Cooper, Edgett e Kleinschmidt (2001), Archer e Ghasemzadeh (1999) e Kavadias (2001), que têm contribuído para a evolução da GP, são os mais citados na literatura. Os modelos de GP constituem-se em etapas a serem realizadas passo a passo e parecem apresentar um ponto em comum: o sucesso depende da escolha dos critérios para a seleção dos projetos, os quais devem ser avaliados por cada empresa (MOREIRA, 2008). Para efetuar essa seleção de projetos são utilizadas técnicas ou ferramentas que auxiliarão na tomada de decisão sobre o portfólio de projetos ou produtos.

A literatura apresenta distintas técnicas para operacionalizar a GP, entretanto a escolha deve considerar a facilidade de uso, o tempo e os recursos disponíveis. Conforme Moreira (2008), dentre as várias ferramentas e técnicas encontradas na literatura, podemos citar: o Q-sort e o AHP (Analytical Hierarchy Process), que são modelos que relacionam um projeto com outro, permitindo hierarquizar a tomada de decisão; os modelos de pontuação ou scoring models, que permitem priorizar os projetos através da pontuação por critérios previamente definidos; os modelos econômicos tradicionais, que relacionam custo-benefício e risco da realização do projeto. Técnicas de programação matemática como a programação linear e a regressão linear também podem ser citadas como técnicas ou ferramentas atrativas para a seleção de projetos.

A matriz BCG, o diagrama de bolhas e a matriz de classificação são exemplos de ferramentas qualitativas que empregam gráficos, diagramas e classificações para auxiliar o processo de gestão do portfólio de produtos (KERZNER, 2006; PROJECT..., 2006; DANILEVICZ, 2006; KOTLER, 1998). Apesar dessa diversidade de opções, não é fácil determinar a utilidade de um ou outro método. Dutra (2007) conclui que é possivel usar mais de um método de modo sinérgico e complementar.

Dentre as alternativas citadas na literatura, duas ferramentas podem ser destacadas. A primeira é o DEIN (modelo de decisão estratégica de inovação em produtos) desenvolvido por Danilevicz (2006), que segue o modelo tradicional do scoring model, caracterizado como tendo a principal vantagem ser de fácil compreensão e aplicação. 0 DEIN visa contribuir na definição de um portfólio mais adequado para o negócio à medida que propõe incorporar em suas etapas as ações estratégicas para a tomada de decisão sobre o PDP, a fim de fornecer maior objetividade à análise de portfólio. Além disso, o DEIN foi criado como um modelo multiplicativo, com o intuito de dar continuidade somente a ideias que sejam relevantes ao negócio e exequíveis. Monteiro (2003) argumenta que modelos de pontuação (scoring models) podem ser criticados como simplistas demais ou tendenciosos. 0 argumento se deve ao fato de que em alguns modelos de pontuação o número atribuído a dado projeto é obtido pela operação de adição simples ou, mais frequentemente, pela ponderação atribuída por avaliadores a critérios individuais. Embora seja fácil de implementar e compreender, tal tipo de método de avaliação não é muito confiável e defensável. Entretanto, dados demonstram que em média 90\% das priorizações por esses métodos são consistentes com os métodos econômicos (MOREIRA, 2008).

O DEIN emprega três indicadores de competitividade, a saber: índice de exequibilidade ideia $\left(I E j_{I d e i a}\right)$, indice de competitividade atual $\left(I C j_{\text {Atua }}\right)$ e índice de competitividade das inovações propostas $\left(I C j_{\text {Inova }}\right)$. É com base nesses índices que os produtos existentes e as ideias de novos produtos serão analisados. Ao final da análise tem-se um portfólio pré-definido para o próximo período, com a descriminação dos produtos que devem ser aposentados, mantidos e inovados.

Outra ferramenta que merece ênfase é a PAMP (planilha para avaliação multicriterial de investimentos), 
que faz parte de uma sistemática ou método de apoio à análise multicriterial de investimentos desenvolvida por Souza (2008). Ela foi projetada a partir da necessidade de acrescentar à análise econômico-financeira de projetos outros fatores que influenciam a tomada de decisão, como fatores qualitativos oriundos do alinhamento estratégico e racionamento de capital, por exemplo, Souza (2008). Modelos econômicofinanceiros são criticados por não englobarem critérios tão importantes quanto o critério financeiro, como a sinergia entre os produtos existentes na empresa, as aspirações estratégicas e a capacidade tecnológica disponivel (DUTRA, 2007). No desenvolvimento da PAMP foram incorporados métodos como o VPL (valor presente líquido) e o NCIC (Non-Traditional Capital Investment Criteria), a fim de quantificar em termos monetários os critérios qualitativos importantes para a empresa, conduzindo a uma determinação ótima do portfólio de projetos. Com isso consegue-se fazer até duas priorizações baseadas ( $i$ ) nos resultados do VPL de cada projeto e (ii) nos resultados de VPL agregado, o qual considera os fatores qualitativos inseridos na análise multicriterial.

A ferramenta PAMP possibilita ainda uma análise de sensibilidade do VPL frente à taxa mínima de atratividade (TMA) da empresa e do impacto da TMA ante o payback descontado do projeto (SOUZA, 2008). A PAMP fornece também os indicadores TIR (taxa interna de retorno), TIRM (taxa interna de retorno modificada) e payback (período de retorno do capital), os quais são calculados conforme tradicionalmente apresentados na literatura e permitem a realização de outras análises a critério dos tomadores de decisão (CASAROTTO FILHO; KOPITTKE, 2000; SOUZA, 2008).

\subsection{Análise das ferramentas DEIN e PAMP}

Interessa neste artigo analisar com maior detalhamento as ferramentas DEIN e PAMP frente à sua aplicabilidade na GP. Assim, o Quadro 1 apresenta um comparativo entre as etapas típicas da GP (DUTRA,

Quadro 1. Comparação das ferramentas DEIN e PAMP quanto ao atendimento das etapas típicas da gestão de portfólio.

\begin{tabular}{lcc}
\hline Etapas de Gestão de Portfólio & DEIN & PAMP \\
\hline ldentificação & X & \\
Categorização & $X$ & $X$ \\
Avaliação & $X$ & $X$ \\
Seleção & $X$ & $X$ \\
Priorização & $X$ & $X$ \\
Balanceamento & & \\
Autorização* & $X$ & $X$ \\
Revisão & $X$ & \\
\hline
\end{tabular}

*A etapa de autorização está coberta pela participação da alta administração, denominado de Equipe de Decisão na PAMP e Time de Desenvolvimento de Negócios no DEIN.
2007) e o atendimento dessas etapas pelas referidas ferramentas.

A sistemática completa desenvolvida por Souza (2008) contém quatro fases de desenvolvimento que não foram abordadas nesta revisão bibliográfica, sejam elas ( $(l)$ ldentificação dos projetos a serem avaliados; (ii) Avaliação econômica dos projetos identificados; (iii) Priorização dos projetos e seleção do portfólio; e (iv) Acompanhamento dos projetos selecionados. Essas fases cobrem todas as oito (8) etapas da GP apresentadas no Quadro 1. Entretanto, a ferramenta PAMP (SOUZA, 2008), que faz parte da sistemática e que está em análise neste artigo, cumpre apenas algumas das etapas da GP, conforme explicitado no Quadro 1.

0 modelo completo de decisão proposto na ferramenta DEIN apresenta também quatro fases, chamadas macroetapas, que se dividem em: (i) Abertura à inovação; (ii) Indução à inovação; (iii) Pré-definição de portfólio; e (iv) Avaliação da inovação. Nesse caso, a etapa de balanceamento de projetos não é formalmente realizada. Contudo, é proposta uma avaliação quanto ao alinhamento do portfólio preliminar com o perfil estratégico de inovação desejado pela empresa, o que caracteriza a ênfase em inovação dessa ferramenta, fazendo um contraponto à ênfase econômicofinanceira da ferramenta PAMP.

Em vista dessas características, a pretensão deste trabalho é traçar um comparativo entre essas duas ferramentas, a fim de elucidar sua aplicabilidade. Em outras palavras, sabe-se que elas apresentam o mesmo objetivo final, a definição de um portfólio de produtos, entretanto, apresentam fundamentações operacionais distintas. Pretende-se testar a consistência entre modelos de pontuação e modelos econômicos pela comparação do ranking de projetos resultantes da aplicação da ferramenta DEIN e da ferramenta PAMP.

\section{Metodologia}

Quanto ao procedimento técnico, o método de pesquisa adotado foi o estudo de caso, que se caracteriza por investigar um fenômeno dentro do seu contexto real, permitindo assim um conhecimento mais apurado do objeto de pesquisa (YIN, 2005). Quanto ao objetivo do estudo, a pesquisa tem caráter descritivo, envolvendo uma pesquisa bibliográfica e a análise comparativa entre duas ferramentas aplicadas sequencialmente na GP de uma empresa. Segundo Köche (1997), a pesquisa descritiva constata e avalia as relações entre variáveis pré-existentes, descrevendo suas características. Como instrumento de coleta de dados primários foram utilizadas as planilhas que compõem as ferramentas DEIN e PAMP, em entrevistas 
aos administradores da empresa sob estudo. Outras informações foram coletadas como dados secundários, a partir de dados históricos e documentos da empresa.

Diferente do uso do estudo de caso como metodologia para construção e teste de uma teoria, o presente trabalho usa esses recursos metodológicos para comparar a aplicabilidade das ferramentas DEIN e PAMP, desenvolvidas no meio acadêmico. 0 estudo foi realizado a partir da experimentação das duas ferramentas numa mesma empresa, visando a comparação dos resultados obtidos. A partir da amostra estudada, pretende-se elucidar a comparatibilidade e aplicabilidade das ferramentas investigadas.

\subsection{Descrição da empresa}

A empresa em estudo é uma indústria do setor alimentício, de pequeno porte e familiar, da área de panificação. A escolha da empresa se justifica pela necessidade latente na mesma de realizar formalmente a gerência do portfólio de produtos, a fim de manter-se no mercado que, ano após ano, se torna mais competitivo. Além disso, a aplicação de ferramentas de GP pode trazer vantagem competitiva para empresas de pequeno porte.

Conforme apresentado no Quadro 2, trata-se de uma empresa na qual todas as decisões estratégicas e táticas são definidas pelo gerente geral, tendo como

Quadro 2. Dados da empresa foco do estudo de caso.

\begin{tabular}{|c|c|}
\hline \multicolumn{2}{|c|}{ Caracterização da Empresa } \\
\hline Tipologia de empresa: & seguidora de mercado \\
\hline Área de atuação: & fabricação e distribuição de pães \\
\hline Planejamento estratégico: & informal \\
\hline PDP: & não estruturado \\
\hline $\begin{array}{l}\text { Ferramenta de análise de } \\
\text { portfólio em uso: }\end{array}$ & não \\
\hline $\begin{array}{l}\text { Conhecimentos associados ao } \\
\text { TDN: }\end{array}$ & $\begin{array}{l}\text { vendas, faturamento, estratégia } \\
\text { empresarial, finanças, portfólio } \\
\text { atual, conhecimento fabril/técnico }\end{array}$ \\
\hline Número de Produtos existentes: & 9 \\
\hline Número de ideias em avaliação: & 8 \\
\hline $\begin{array}{l}\text { Número de projetos de novos } \\
\text { produtos avaliados: }\end{array}$ & 14 \\
\hline
\end{tabular}

conselheiro um colaborador qualificado, em virtude do porte. 0 levantamento de dados e as respostas aos questionamentos foram realizados por eles, aqui denominados Time de desenvolvimento de negócios (TDN), conforme sugerido por (DANILEVICZ, 2006).

\subsection{Etapas do método de trabalho}

- Revisão da literatura: a primeira etapa da pesquisa consistiu na revisão da literatura sobre os assuntos relacionados ao trabalho, GP e ferramentas utilizadas para essa gestão;

- Contato com a empresa e levantamento de informações: a empresa foi contatada primeiramente por telefone. Nessa ocasião, os objetivos do trabalho foram brevemente explicados e foi solicitado que todas as informações relevantes acerca de cada produto ou processo existente fossem revisadas e trazidas para as próximas reuniões;

- Aplicação das ferramentas DEIN e PAMP: as ferramentas foram aplicadas em momentos diferentes, com o objetivo de minimizar possível viés na pesquisa comparativa entre as ferramentas. Foram avaliadas as etapas de abertura à inovação até a pré-definição de portfólio do DEIN e da PAMP propriamente dita. Antes de iniciar a aplicação das ferramentas foi ministrado um pequeno treinamento para garantir que os conceitos utilizados durante o trabalho fossem entendidos. Além disso, a estratégia da empresa foi discutida a fim de definir-se formalmente e permitir que seja feita a devida associação aos projetos durante a avaliação. Um resumo das atividades realizadas para a aplicação das ferramentas está apresentado no Quadro 3. Por questões didáticas, as planilhas e formas de cálculo das ferramentas DEIN e PAMP serão apresentadas junto aos resultados do trabalho no item 4;

- Análise comparativa dos resultados das ferramentas: a última etapa proposta consiste na análise comparativa dos resultados obtidos com a aplicação do DEIN e da PAMP. Deve ser avaliado o ranking de projetos gerados por cada uma, assim como os aspectos relevantes quanto às causas de possíveis diferenças.

Quadro 3. Resumo das atividades do estudo de caso.

\begin{tabular}{|c|c|c|}
\hline Contato & Tipo de contato & Atividades realizadas \\
\hline 1 & Contato telefônico & $\begin{array}{l}\text { Apresentação dos objetivos do trabalho e das atividades necessárias, explicação sobre as informações } \\
\text { necessárias para a primeira reunião do DEIN (dados dos produtos atuais e banco de ideias). }\end{array}$ \\
\hline 2 & Visita & $\begin{array}{l}\text { Levantamento da situação atual e das ideias, discussão sobre a estratégia da empresa, apresentação/ } \\
\text { treinamento do DEIN. }\end{array}$ \\
\hline 3 & Visita (duas sessões) & Preenchimento das matrizes do DEIN e discussão sobre os critérios. \\
\hline 4 & Visita & Apresentação/treinamento da PAMP, definição de atributos qualitativos e dados de entrada necessários. \\
\hline 5 & Contato telefônico & Acompanhamento dos orçamentos. \\
\hline 6 & Visita & Coleta dos dados de entrada para a PAMP. \\
\hline 7 & Visita & Coleta de dados para análise multicriterial da PAMP. \\
\hline
\end{tabular}


Os mesmos projetos foram avaliados com as duas ferramentas a fim de possibilitar tal comparação.

\section{Resultados e discussão}

Conforme mencionado no item 3.2, a empresa foi contatada e os objetivos do trabalho foram brevemente explicados. As informações relevantes acerca de cada produto ou processo existente foram revisadas e disponibilizadas nas reuniões subsequentes. Foi salientada a importância de considerar, pelo menos, os resultados do último ano fiscal da empresa. Da mesma forma, foram questionados a respeito de banco de ideias para novos produtos ou processos de fabricação e foi solicitado que todas as informações a esse respeito fossem disponibilizadas.

A primeira ferramenta aplicada foi o DEIN e essa atividade teve início em uma reunião de abertura para a apresentação do projeto e da ferramenta para os integrantes do TDN. A aplicação pressupõe o preenchimento de matrizes com ideias de projeto e o cálculo dos indicadores mencionados no item 2.1.

Para elaboração do banco de ideias, o TDN foi questionado em relação a oportunidades de novos produtos e projetos, sendo apresentadas três possibilidades para aumentar o faturamento em curto e médio prazos. A primeira seria implantar uma linha de pães congelados para distribuição a micro e pequenas empresas. Essa é uma nova realidade do negócio de distribuição de pães na qual a empresa já estava atrasada e necessitando atendê-la para se manter competitiva. Entretanto, para que esse projeto pudesse ser realizado, fazia-se necessário investimento em equipamentos específicos, num montante não disponível para a empresa. A segunda possibilidade seria entrar na área de varejo, abrindo um ponto de venda. Para essa opção, fazia-se necessária uma reforma no prédio, a fim de criar uma área atraente e minuciosamente pensada para facilitar a compra. A ideia era seguir a estratégia das grandes redes de supermercados, que trouxeram para o setor de padaria o conceito ilhas de solução (GIRO..., 2008), oferecendo ao cliente tudo que ele precisa, concentrando em um mesmo lugar o acesso a produtos que guardam alguma correlação. A terceira alternativa seria continuar com a distribuição realizada então e incrementar o mix com produtos mais atraentes, como uma linha de produtos light e oferecer produtos em embalagem menor, sugerindo a ideia do "pronto para comer".

Assim, o TDN citou oito idéias para novos produtos/ projetos. Os projetos apresentados pela empresa têm como principal motivo as transformações por que o setor de panificação tem passado nos últimos anos. Conforme podem ser verificadas na Tabela 1, as ideias são condizentes com a tendência no setor (GIRO..., 2008), são lançadas nas colunas da matriz e incluem: linha de produtos light, congelados e ponto-de-venda com produtos prontos para refeição rápida.

Alguns fatos associados à aplicação do DEIN merecem destaque. Um deles refere-se ao nível de preparação da empresa no que tange à tomada de decisão sobre a inovação. 0 TDN encontrou dificuldades relacionadas à análise de alguns critérios existentes na primeira planilha da ferramenta (Tabela 1), o que pode ser justificado pelo estágio de maturidade da empresa em relação ao PDP e à estratégia voltada à inovação.

Conforme se observa na Tabela 1, os critérios que o TDN deve avaliar para cada produto/projeto estão agrupados, nas linhas, sob os descritores: estratégia, lucratividade, implantação e tempo. 0 indice de exequibilidade da ideia é calculado através da Equação 1.

$$
\begin{aligned}
& I E j_{\text {Idéia }}=\frac{(C 1 j+C 2 j+C 3 j)}{15} \times \frac{C 4 j}{5} \times \\
& \frac{(C 5 j+C 6 j+C 7 j+C 8 j)}{20} \times \\
& \frac{(C 9 j+C 10 j+C 11 j)}{15}
\end{aligned}
$$

onde:

- $I E j_{l d e i a}=$ Índice de exequibilidade da idéia j;

- $C i j$ = Pontuação atribuída ao critério i na avaliação da ideia j.

Considerando-se que os valores usados na pontuação dos critérios Cij são 1 a 9, se todos os critérios receberem avaliação no centro da escala (5), o resultado será igual ao valor 1 . Se os critérios receberem o valor de pontuação superior ao centro da escala, o índice de exequibilidade será maior que 1 e, se receberem valores de pontuação inferiores ao centro da escala, o índice será menor que 1.0 maior valor que o índice assumirá será aproximadamente 10 e o valor mínimo igual a 0 (zero). A intenção dos autores ao adotar um modelo multiplicativo foi penalizar a pontuação geral de ideias de projeto que tenham pontuação muito baixa em relação aos critérios estabelecidos. Dessa forma a ferramenta permite que sejam continuadas somente as ideias relevantes e exequíveis. Um modelo aditivo permitiria que ideias "apenas relevantes" ou "apenas exequiveis" recebessem pontuação moderada e, eventualmente, pudessem ser conduzidas a etapas posteriores de desenvolvimento.

Devido à impossibilidade de seguir fielmente o modelo de aplicação proposto, é possível que haja algum viés relacionado ao modo como as matrizes 
Tabela 1. Matriz de avaliação da exequibilidade das ideias da ferramenta DEIN.

\begin{tabular}{|c|c|c|c|c|c|c|c|c|}
\hline \multirow{2}{*}{$\begin{array}{l}\text { Matriz de avaliação da exequibilidade das ideias } \\
\text { Dimensões e Critérios - Exequibilidade Ideias }\end{array}$} & \multicolumn{8}{|c|}{ Banco de ideias } \\
\hline & 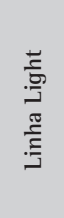 & 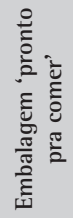 & 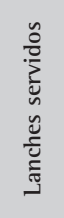 & 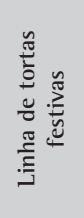 & 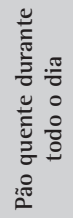 & 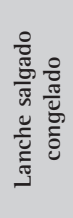 & 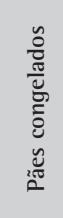 & 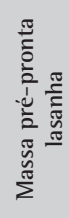 \\
\hline \multicolumn{9}{|l|}{ Estratégia } \\
\hline Impacto das inovações no restante do portfólio & 8 & 8 & 9 & 7 & 9 & 8 & 8 & 8 \\
\hline Contribuição das inovações no atingimento das estratégias & 8 & 8 & 5 & 5 & 5 & 8 & 9 & 8 \\
\hline Grau de risco de desenvolvimento da nova idéia & 6 & 4 & 1 & 3 & 3 & 8 & 8 & 6 \\
\hline Impacto social e ambiental & 9 & 9 & 9 & 9 & 9 & 9 & 9 & 8 \\
\hline \multicolumn{9}{|l|}{ Lucratividade } \\
\hline Previsão de vendas e faturamento & 8 & 8 & 9 & 7 & 9 & 8 & 7 & 7 \\
\hline \multicolumn{9}{|l|}{ Implantação } \\
\hline Análise de patente (existência/custo) & 9 & 9 & 9 & 9 & 9 & 9 & 9 & 9 \\
\hline Existência de tecnologia para desenvolver a ideia & 9 & 5 & 6 & 4 & 9 & 8 & 2 & 8 \\
\hline Existência de competência para desenvolver a ideia & 9 & 9 & 5 & 8 & 8 & 8 & 6 & 7 \\
\hline Investimento potencial do desenvolvimento & 9 & 8 & 1 & 8 & 8 & 9 & 5 & 1 \\
\hline \multicolumn{9}{|l|}{ Tempo } \\
\hline Tempo de ciclo de desenvolvimento do produto & 8 & 8 & 5 & 7 & 8 & 7 & 7 & 8 \\
\hline Tempo até a aceitação da inovação no mercado & 9 & 9 & 9 & 9 & 9 & 9 & 9 & 9 \\
\hline Tempo de replicação da inovação pela concorrência & 1 & 5 & 9 & 2 & 8 & 4 & 8 & 6 \\
\hline Índice de Exequibilidade Ideia $\left(I E j_{\text {ldeia }}\right)$ & 5,13 & 5,63 & 5,58 & 3,10 & 8,03 & 5,72 & 4,29 & 4,12 \\
\hline
\end{tabular}

Fonte: adaptado de Danilevicz (2006).

do DEIN foram preenchidas. Primeiramente, pelo fato do TDN ser formado por apenas duas pessoas que, apesar de possuírem conhecimento total da empresa e dos processos nela inseridos, podem ser simplistas demais nas avaliações técnicas. Apesar de representar um ruído para a análise, o número reduzido de administradores é uma característica de empresas de pequeno porte e poderá ocorrer em aplicações futuras em empresas semelhantes. Outro fato é que a empresa não pode ser considerada uma empresa inovadora radical, mas sim aquela que tem projetos que visam inovações incrementais, seja em novos produtos ou novos negócios, almejando sua sustentabilidade no mercado. Da mesma forma, muito ainda precisa ser feito no sentido de estruturar o PDP e traduzir os objetivos da empresa num planejamento estratégico bem definido.

A Tabela 2 apresenta os indicadores de competitividade para os produtos existentes e novos. Os índices $I C j_{\text {Atual }}$ e $I C j_{\text {Inova }}$ são calculados através das Equações 2 e 3.

$I C j_{\text {Atual }}=\frac{A 1 j}{5} \times \frac{A 2 j}{5} \times \frac{(A 3 j+A 4 j)}{10} \times \frac{A 5 j}{5}$

Onde:

- $I C j_{\text {Atual }}=$ Índice de competitividade atual do produto j; $A i j=$ Avaliação do produto $\mathrm{j}$ em relação ao critério i.
$0 I C j_{\text {Atual }}$ (Equação 2) representa a situação em que se encontra o produto perante o portfólio de negócios da empresa. Associado ao seu resultado existe uma linha tênue entre um produto que está prestes a ser aposentado e outro que demanda inovações. 0 fator que irá esclarecer em qual das duas situações se encontra o produto é o índice de competitividade das inovações propostas no produto $I C j_{\text {lnova }}$ (Equação 3), que é resultado da análise do cenário de exequibilidade do produto. Novamente, o modelo multiplicativo é usado, uma vez que um critério não relevante gera uma pontuação baixa ou nula e a ideia não é conduzida a etapas posteriores de desenvolvimento.

$$
\begin{aligned}
& I C j_{\text {lnova }}=\frac{(A 6 j+A 7 j)}{10} \times \\
& \frac{(A 8 j+A 9 j+A 10 j)}{15} \times \frac{A 11 j}{5} \times \\
& \frac{(A 12 j+A 13 j+A 14 j)}{15} \times \frac{(A 15 j+A 16 j)}{10}
\end{aligned}
$$

Onde:

- $I C j_{\text {lnova }}$ I Índice de competitividade da inovação proposta no produto j;

- $A i j$ = Avaliação da inovação proposta considerando o critério i. 
Tabela 2. Índice de competitividade para produtos atuais e proposta de novos produtos.

\begin{tabular}{|c|c|c|c|c|c|}
\hline Projeto & Produtos Atuais & $1 \mathrm{Cj}_{\text {Atual }}$ & Projeto & Proposta de novos Produtos & $1 \mathrm{Cj}_{\text {Inova }}$ \\
\hline \multirow[t]{2}{*}{15} & pão francês & 3,76 & 6 & pão francês quente durante todo dia & 7,04 \\
\hline & & & 9 & pão francês congelado & 5,27 \\
\hline \multirow[t]{3}{*}{16} & pão doce & 3,76 & 7 & pão doce quente durante todo dia & 7,04 \\
\hline & & & 10 & pão doce congelado & 4,14 \\
\hline & & & 1 & bisnaguinha light embalagem pronto pra comer & 8,59 \\
\hline 17 & pão sanduiche tradicional & 2,23 & 2 & pão sanduiche light & 9,87 \\
\hline 18 & pão para xis/cachorro-quente & 5,24 & 11 & pão xis/cachorro congelado & 3,96 \\
\hline 19 & pão de centeio & 0,86 & 3 & pão centeio light & 9,32 \\
\hline 20 & Cucas & 0,36 & & & \\
\hline \multirow[t]{2}{*}{21} & pão erva-doce & 1,44 & 8 & pão erva-doce quente durante o dia & 5,90 \\
\hline & & & 12 & pão erva-doce congelado & 2,42 \\
\hline 22 & pão para torta-fria & 4,78 & 4 & pão torta-fria light & 8,77 \\
\hline \multirow[t]{3}{*}{23} & bolo chá das 5 & 1,26 & 5 & bolo chá das 5 pronto para comer & 5,67 \\
\hline & & & 13 & lanche salgado congelado & 7,84 \\
\hline & & & 14 & lanches servidos & 6,47 \\
\hline Mediana & & 2,23 & Mediana & & 6,76 \\
\hline
\end{tabular}

A partir dos resultados apresentados na Tabela 2 foi possível distribuir os produtos nos quadrantes propostos pela ferramenta, quais sejam: (1) definitivamente promover a inovação, (2) promover a inovação e/ou manter o atual, (3) manter o produto como está, (4) aposentar o produto, retirando-o do portfólio, conforme mostra a Quadro 4.

Neste trabalho, a linha de corte associada aos indicadores que caracterizam baixa ou alta competitividade (DANILEVICZ, 2006) foi o valor mediano dos índices, conforme sugerido como primeira escolha pela autora da ferramenta. Entretanto, essa é uma decisão do TDN. Com isso, pode-se aumentar ou diminuir desde o número de ideias exequíveis até o número de produtos que sairão do portfólio, dependendo da análise crítica da empresa sobre os resultados encontrados. Neste estudo, apesar da utilização da mediana, optou-se por manter a linha de pães congelados, que ficou com $I E j_{\text {Ideia }}$ de 4,29 contra os 5,35 da mediana (Tabela 1). Da mesma forma, na pré-definição de portfólio (Quadro 4), o produto bolo chá das 5 poderia ser promovido à inovação no quadrante 1 , pois o $I C j_{\text {lnova }}$ foi maior que o $I C j_{\text {Atuar }}$ Entretanto, como os dois ficaram abaixo da mediana de seu respectivo índice, o TDN decidiu que eles ficariam no quadrante 4 até nova análise.

A reunião subsequente foi destinada à aplicação da ferramenta PAMP, iniciada uma semana após a realização do DEIN. A PAMP foi aplicada para os mesmos projetos avaliados com o DEIN. Devido ao DEIN incluir na análise do portfólio produtos existentes e produtos novos, os mesmos foram também analisados na PAMP, para permitir comparação posterior dos resultados das duas ferramentas. Durante as semanas subsequentes, diversos orçamentos foram realizados, de acordo com a lista de investimentos necessários em equipamentos, móveis, utensílios, reformas, veículos e outros, para cada projeto, a fim de preencher a planilha e permitir a montagem do fluxo de caixa.

Conforme identificado por Souza (2008), a grande dificuldade na aplicação dessa ferramenta e, provavelmente, 0 aspecto que mais tem possibilidade de induzir ao erro é a projeção do fluxo de caixa para as oportunidades de projeto. 0 fato da PAMP utilizar o VPL (valor presente líquido) para priorizar os projetos exige que receitas e despesas sejam bem projetadas ou estimadas, com pena da análise não corresponder à realidade. Devido ao fato de não existir na panificadora relatório contendo todos os custos e receitas bem documentados, foram necessários grandes esforços para obter dados confiáveis para a análise. Além disso, a empresa ou o TDN deve definir uma TMA (taxa mínima de atratividade), que consiste no custo do capital atribuído à empresa, isto é, uma taxa que reflete o custo de oportunidade dos investidores, de forma a compensar os riscos envolvidos no momento em que se opta por implementar o projeto avaliado (SOUZA, 2008). 0 uso de uma TMA inadequada pode prejudicar a análise de um projeto, influenciando no portfólio da empresa. Neste trabalho, a TMA definida pelo TDN foi de 10\%. Após a organização dos custos e receitas de cada projeto com formação do fluxo de caixa, foram realizadas duas priorizações sequenciais com a PAMP, conforme previsto na metodologia. A primeira, em função dos VPLs obtidos para cada projeto (análise puramente econômico-financeira). A segunda, em função dos VPLs agregados, onde já estão incorporados os aspectos qualitativos. A terceira priorização sugerida pela sistemática em questão, através da programação 
linear, não foi realizada, visto que o ranqueamento que considera os atributos qualitativos já é satisfeito com a análise multicriterial, sendo uma opção da empresa prosseguir ou não para a próxima fase. A Tabela 3 mostra os resultados da aplicação da ferramenta PAMP com o ranking dos produtos, considerando:

Quadro 4. Pré-definição do portfólio da panificadora segundo DEIN.

\begin{tabular}{|c|c|c|}
\hline & $\begin{array}{l}\text { Pouca possibilidade de } \\
\text { inovação }-1 \mathrm{ICj}_{\text {novo }} \text { baixo }\end{array}$ & $\begin{array}{l}\text { Boas possibilidades de } \\
\text { inovação }-1 \mathrm{ICj}_{\text {novo }} \text { alto }\end{array}$ \\
\hline 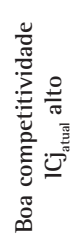 & $\begin{array}{c}\text { (3) } \\
\text { pão de xis/cachorro-quente }\end{array}$ & $\begin{array}{c}\text { (2) } \\
\text { pão para torta-fria } \\
\text { pão francês } \\
\text { pão doce }\end{array}$ \\
\hline 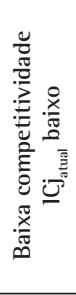 & $\begin{array}{l}\text { (4) } \\
\text { pão erva-doce } \\
\text { bolo chá das } 5 \\
\text { cucas }\end{array}$ & $\begin{array}{c}\text { (1) } \\
\text { pão sanduíche } \\
\text { pão centeio }\end{array}$ \\
\hline s quad & $\begin{array}{l}\text { ntes estão distribuidos da } \\
\text { ante promover a inovação; quadr } \\
\text { o atual; quadrante (3) manter o } \\
\text { produto, retirando-o do portfóli }\end{array}$ & $\begin{array}{l}\text { guinte forma: quadrante (1) } \\
\text { te (2) pode promover a inovação } \\
\text { roduto como está; quadrante (4) }\end{array}$ \\
\hline
\end{tabular}

(a) somente a análise econômico-financeira através do VPL e; (b) considerando os atributos qualitativos incorporados à análise econômico-financeira pela análise multicriterial através do VPL agregado. Optou-se por não detalhar os cálculos desses indicadores, visto que estão consagrados na literatura (BREALEY; MYERS, 1991; SMART; MEGGINSON; GITMAN, 2004).

Apesar da ferramenta PAMP permitir que sejam identificados os projetos contingentes (dependentes), algumas análises podem ser prejudicadas quanto a esse critério. 0 fato de alguns investimentos serem divididos, caso vários produtos de uma mesma linha sejam lançados, deve ser levado em consideração, conforme se descreve. Por exemplo, o custo do forno turbo a gás necessário para os projetos relacionados à oferta de pão quente o dia inteiro no ponto de venda (projetos 6, 7 e 8) pode ser dividido por três se for considerado que os três tipos de pães serão fabricados. Entretanto, analisando os três produtos separadamente, o projeto não foi viável financeiramente, considerando a TMA definida pela empresa, o que também ocorreu com os projetos de pães congelados $(9,10,11,12$ e 13), onde o investimento inicial em equipamentos e veículos é alto. Essa situação poderá ser vista no caso de produtos que compartilham os mesmos equipamentos ou outro investimento inicial, como reformas, por exemplo. Dessa forma, de posse dos resultados da planilha, o gestor deve analisar caso

Tabela 3. Ranking preliminar dos produtos da panificadora segundo resultados do VPL e do VPL agregado.

\begin{tabular}{llll}
\hline & \multicolumn{1}{c}{ Projeto } & Primeira priorização (VPL) & Segunda priorização (VPL agregado) \\
\hline 02 & Pão sanduiche light & $\mathrm{R} \$ 198.819,01$ & $\mathrm{R} \$ 419.186,01$ \\
05 & Bolo chá das 5 bem pronto pra comer & $\mathrm{R} \$ 68.368,93$ & $\mathrm{R} \$ 358.032,16$ \\
01 & Bisnaguinha light bem pronto pra comer & $\mathrm{R} \$ 132.840,51$ & $\mathrm{R} \$ 224.464,17$ \\
03 & Pão centeio light & $\mathrm{R} \$ 115.598,99$ & $\mathrm{R} \$ 199.520,34$ \\
15 & Pão francês atual & $\mathrm{R} \$ 17.469,43$ & $\mathrm{R} \$ 73.063,33$ \\
14 & Lanches servidos & $\mathrm{R} \$ 6.778,35$ & $\mathrm{R} \$ 67.573,42$ \\
16 & Pão doce atual & $\mathrm{R} \$ 11.754,83$ & $\mathrm{R} \$ 49.162,84$ \\
18 & Paõ xis cachorro atual & $\mathrm{R} \$ 11.720,57$ & $\mathrm{R} \$ 45.641,11$ \\
19 & Pão centeio atual & $\mathrm{R} \$ 10.424,47$ & $\mathrm{R} \$ 43.598,83$ \\
17 & Pão sanduiche tradicional atual & $\mathrm{R} \$ 16.275,07$ & $\mathrm{R} \$ 30.519,18$ \\
04 & Pão torta-fria light & $\mathrm{R} \$ 14.503,46$ & $\mathrm{R} \$ 30.472,11$ \\
22 & Pão torta-fria atual & $\mathrm{R} \$ 1.653,58$ & $\mathrm{R} \$ 6.439,23$ \\
23 & Bolo chá das 5 atual & $\mathrm{R} \$ 704,59$ & $\mathrm{R} \$ 2.946,85$ \\
10 & Pão doce congelado & $(\mathrm{R} \$ 2.772,72)$ & $(\mathrm{R} \$ 1.080,59)$ \\
20 & Cuca & $(\mathrm{R} \$ 1.207,01)$ & $(\mathrm{R} \$ 2.263,40)$ \\
21 & Pão erva-doce atual & $(\mathrm{R} \$ 1.438,91)$ & $(\mathrm{R} \$ 2.698,26)$ \\
07 & Pão doce quente & $(\mathrm{R} \$ 44.656,90)$ & $(\mathrm{R} \$ 3.122,75)$ \\
06 & Pão francês quente & $\mathrm{R} \$ 47.664,29)$ & $(\mathrm{R} \$ 3.333,05)$ \\
09 & Pão francês congelado & $(\mathrm{R} \$ 8.962,92)$ & $(\mathrm{R} \$ 3.493,06)$ \\
08 & Pão erva-doce quente & $(\mathrm{R} \$ 54.608,78)$ & $(\mathrm{R} \$ 3.818,66)$ \\
24 & Torta festiva & $(\mathrm{R} \$ 38.695,72)$ & $(\mathrm{R} \$ 6.300,51)$ \\
25 & Massa pré-pronta lasanha & $(\mathrm{R} \$ 27.048,19)$ & $(\mathrm{R} \$ 8.392,33)$ \\
13 & Lanche salgado congelado & $(\mathrm{R} \$ 104.451,01)$ & $(\mathrm{R} \$ 40.707,00)$ \\
12 & Pão xis cachorro congelado & $(\mathrm{R} \$ 132.413,13)$ & $(\mathrm{R} \$ 51.604,50)$ \\
11 & Pão erva-doce congelado & $\mathrm{R} \$ 71.021,34)$ & $(\mathrm{R} \$ 250.173,45)$ \\
\hline
\end{tabular}


a caso e uma nova planilha deve ser gerada com os custos de investimento divididos entre o número de produtos que usufruirão dele. Nesse caso, deve-se tomar o cuidado de analisar os VPLs de todos os produtos juntos. Outra possibilidade seria juntar todos os produtos que têm o mesmo investimento inicial em uma única planilha e verificar o retorno. Essa é uma grande vantagem da PAMP, pois se podem montar cenários com os diversos projetos e verificar se um projeto não viável sozinho se tornará viável quando implementado junto com outros.

$\mathrm{Na}$ Tabela 4 podem ser verificados os novos VPLs e VPLs agregados quando os produtos e investimentos foram agrupados em um mesmo projeto, chamados pães quentes (projeto 00) e pães congelados (projeto 000). A análise da tabela comprova que alguns projetos de produtos isolados não são viáveis, mas, à medida que outros produtos são incorporados à análise, o mesmo se torna compatível dentro do que foi estipulado previamente pela empresa como viável. A partir desse resultado, ressalta-se novamente a importância da exatidão e precisão dos dados de entrada para a correta análise quanto ao futuro do portfólio da empresa.

Após a aplicação das duas ferramentas, procedeu-se a uma análise comparativa dos resultados obtidos. Uma vez que as ferramentas expressam seu resultado final de forma diferente, criou-se um novo quadro comparando os resultados finais delas (Tabela 5). Para isso foram considerados os índices de competitividade calculados no DEIN de forma a criar o ranking dessa ferramenta. 0 ranking DEIN assim obtido foi condizente com os resultados da Quadro 4
Através da Tabela 5 pode-se inferir que as ferramentas são comparáveis, levando a um ranking de projetos de novos produtos parecidos, porém a priorização não é exatamente a mesma. É preciso considerar que a título de comparação utilizaram-se os VPLs agregados dos projetos 6, 7 e 8 (produtos quentes) e $9,10,11,12$ e 13 (produtos congelados) distintamente, ignorando o fato de que se fossem agrupados nos projetos 00 e 000 teriam desempenho bem melhor no ranking da ferramenta PAMP. Portanto, pode-se dizer que o resultado das duas ferramentas foi semelhante. Além disso, o resultado da ferramenta PAMP, por ser quantitativo, auxilia a balizar a decisão de caráter mais qualitativo da ferramenta DEIN. 0 produto 15 (pão francês atual), por exemplo, poderia ser mantido no portfólio com segurança, pois apesar de ter tido ranking relativamente baixo na DEIN, teve valor de VPL agregado consideravelmente interessante na ferramenta PAMP.

Algumas características específicas de cada ferramenta utilizada merecem discussão. O DEIN apresenta a limitação de não ser diretamente aplicável a novos negócios, aplicando-se somente a produtos e processos. Na etapa inicial de levantamento das informações, a primeira intenção foi aplicar as ferramentas de acordo com as ideias principais fornecidas pela empresa, ou seja, projeto linha light, projeto linha de congelados e projeto varejo. Entretanto, para possibilitar a aplicação do DEIN e posterior comparação com a PAMP, considerou-se cada novo produto como um novo projeto. Para a determinação dos atributos intangíveis utilizados na PAMP também foram priorizados sempre os quatro

Tabela 4. Ranking dos produtos da panificadora segundo resultados do VPL agregado considerando projetos de produtos agrupados.

\begin{tabular}{clcc}
\hline & \multicolumn{1}{c}{ Projeto } & Primeira priorização (VPL) & Segunda priorização (VPL agregado) \\
\hline 02 & Pão sanduiche light & $\mathrm{R} \$ 198.819,01$ & $\mathrm{R} \$ 419.186,01$ \\
05 & Bolo chá das 5 bem pronto pra comer & $\mathrm{R} \$ 68.368,93$ & $\mathrm{R} \$ 358.032,16$ \\
01 & Bisnaguinha light bem pronto pra comer & $\mathrm{R} \$ 132.840,51$ & $\mathrm{R} \$ 224.464,17$ \\
03 & Pão centeio light & $\mathrm{R} \$ 115.598,99$ & $\mathrm{R} \$ 199.520,34$ \\
000 & Pães congelados & $\mathrm{R} \$ 137.895,59$ & $\mathrm{R} \$ 155.695,82$ \\
15 & Pão francês atual & $\mathrm{R} \$ 17.469,43$ & $\mathrm{R} \$ 73.063,33$ \\
14 & Lanches servidos & $\mathrm{R} \$ 6.778,35$ & $\mathrm{R} \$ 67.573,42$ \\
00 & Pães quentes & $\mathrm{R} \$ 27.301,42$ & $\mathrm{R} \$ 52.693,71$ \\
16 & Pão doce atual & $\mathrm{R} \$ 11.754,83$ & $\mathrm{R} \$ 49.162,84$ \\
18 & Pão xis cachorro atual & $\mathrm{R} \$ 11.720,57$ & $\mathrm{R} \$ 45.641,11$ \\
19 & Pão centeio atual & $\mathrm{R} \$ 10.424,47$ & $\mathrm{R} \$ 43.598,83$ \\
17 & Pão sanduiche tradicional atual & $\mathrm{R} \$ 16.275,07$ & $\mathrm{R} \$ 30.519,18$ \\
04 & Pão torta-fria light & $\mathrm{R} \$ 14.503,46$ & $\mathrm{R} \$ 30.472,11$ \\
22 & Pão torta-fria atual & $\mathrm{R} \$ 1.653,58$ & $\mathrm{R} \$ 6.439,23$ \\
23 & Bolo chá das 5 atual & $\mathrm{R} \$ 704,59$ & $\mathrm{R} \$ 2.946,85$ \\
20 & Cuca & $(\mathrm{R} \$ 1.207,01)$ & $(\mathrm{R} \$ 2.263,40)$ \\
21 & Pão erva-doce atual & $(\mathrm{R} \$ 1.438,91)$ & $(\mathrm{R} \$ 2.698,26)$ \\
24 & Torta festiva & $(\mathrm{R} \$ 38.695,72)$ & $(\mathrm{R} \$ 6.300,51)$ \\
25 & Massa pré-pronta lasanha & $(\mathrm{R} \$ 27.048,19)$ & $(\mathrm{R} \$ 8.392,33)$ \\
\hline
\end{tabular}


critérios avaliados no DEIN (estratégia, lucratividade, implantação e tempo), exceto a lucratividade, que já era avaliada através do VPL. Assim foi possível a comparação dos mesmos produtos frente aos mesmos critérios. Contudo, a matriz de associação das ideias exequíveis aos produtos existentes do DEIN (Tabela 6) foi essencial nessa etapa inicial, pois os novos produtos ainda não estavam totalmente definidos pelo TDN, apenas as linhas de produtos onde queriam atuar. Os índices $I E j_{I_{\text {ldeia }}}$ são calculados através da Equação 1.
Percebe-se então que as duas ferramentas podem ser complementares entre si, isto é, a análise de produtos existentes é um exercício que não existe na ferramenta PAMP e que contribui para a identificação de oportunidades. Nesse caso, foi possível ampliar o conjunto de novas oportunidades e defini-los, pois uma mesma ideia pode ser aplicada para outros produtos do portfólio, aumentando assim as chances de uma boa ideia se tornar viável economicamente. Essa é

Tabela 5. Comparação do ranking resultante do DEIN e da PAMP.

\begin{tabular}{|c|c|c|c|c|c|}
\hline \multicolumn{3}{|c|}{ Ranking DEIN } & \multicolumn{3}{|c|}{ Ranking PAMP } \\
\hline & Projetos & $1 C j_{\text {Inova/Atual }}$ & & Projetos & VPL agregado \\
\hline 02 & Pão sanduiche light & 9,87 & 02 & Pão sanduiche light & $\mathrm{R} \$ 419.186,01$ \\
\hline 03 & Pão centeio light & 9,32 & 05 & Bolo chá das 5 bem pronto pra comer & $\mathrm{R} \$ 358.032,16$ \\
\hline 04 & Pão torta-fria light & 8,77 & 01 & Bisnaguinha light bem pronto pra comer & $\mathrm{R} \$ 224.464,17$ \\
\hline 01 & Bisnaguinha light bem pronto pra comer & 8,59 & 03 & Pão centeio light & $\mathrm{R} \$ 199.520,34$ \\
\hline 13 & Lanche salgado congelado & 7,84 & 15 & Pão francês atual & $\mathrm{R} \$ 73.063,33$ \\
\hline 06 & Pão francês quente & 7,04 & 14 & Lanches servidos & $\mathrm{R} \$ 67.573,42$ \\
\hline 07 & Pão doce quente & 7,04 & 16 & Pão doce atual & $\mathrm{R} \$ 49.162,84$ \\
\hline 14 & Lanches servidos & 6,47 & 18 & Pão xis cachorro atual & $\mathrm{R} \$ 45.641,11$ \\
\hline 08 & Pão erva-doce quente & 5,90 & 19 & Pão centeio atual & $\mathrm{R} \$ 43.598,83$ \\
\hline 05 & Bolo chá das 5 emb pronto pra comer & 5,67 & 17 & Pão sanduiche tradicional atual & $\mathrm{R} \$ 30.519,18$ \\
\hline 09 & Pão francês congelado & 5,27 & 04 & Pão torta-fria light & $\mathrm{R} \$ 30.472,11$ \\
\hline 18 & Pão xis cachorro atual & 5,24 & 22 & Pão torta-fria atual & $\mathrm{R} \$ 6.439,23$ \\
\hline 22 & Pão torta-fria atual & 4,78 & 23 & Bolo chá das 5 atual & $\mathrm{R} \$ 2.946,85$ \\
\hline 10 & Pão doce congelado & 4,14 & 10 & Pão doce congelado & $(\mathrm{R} \$ 1.080,59)$ \\
\hline 11 & Pão xis cachorro congelado & 3,96 & 20 & Cuca & $(\mathrm{R} \$ 2.263,40)$ \\
\hline 15 & Pão francês atual & 3,76 & 21 & Pão erva-doce atual & $(\mathrm{R} \$ 2.698,26)$ \\
\hline 16 & Pão doce atual & 3,76 & 07 & Pão doce quente & $(\mathrm{R} \$ 3.122,75)$ \\
\hline 12 & Pão erva-doce congelado & 2,42 & 06 & Pão francês quente & $(\mathrm{R} \$ 3.333,05)$ \\
\hline 17 & Pão sanduiche tradicional atual & 2,23 & 09 & Pão francês congelado & $(\mathrm{R} \$ 3.493,06)$ \\
\hline 21 & Pão erva-doce atual & 1,44 & 08 & Pão erva-doce quente & $(\mathrm{R} \$ 3.818,66)$ \\
\hline 23 & Bolo chá das 5 atual & 1,26 & 24 & Torta festiva & $(\mathrm{R} \$ 6.300,51)$ \\
\hline 19 & Pão centeio atual & 0,86 & 25 & Massa pré-pronta lasanha & (R\$ 8.392,33) \\
\hline 20 & Cuca & 0,36 & 13 & Lanche salgado congelado & $(\mathrm{R} \$ 40.707,00)$ \\
\hline 24 & Torta festiva & $N / A$ & 12 & Pão xis cachorro congelado & $(\mathrm{R} \$ 51.604,50)$ \\
\hline 25 & Massa pré-pronta lasanha & $\mathrm{N} / \mathrm{A}$ & 11 & Pão erva-doce congelado & (R\$ 250.173,45) \\
\hline
\end{tabular}

Tabela 6. Associação das ideias exequíveis aos produtos existentes.

\begin{tabular}{|c|c|c|c|c|c|c|c|c|c|c|c|c|}
\hline $\begin{array}{l}\text { Ideias inovação em produtos } \\
\text { e processos existentes }\end{array}$ & 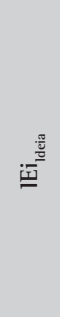 & 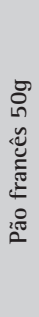 & 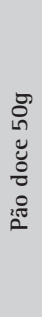 & 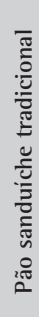 & 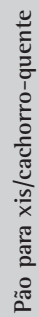 & 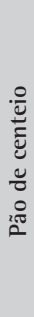 & 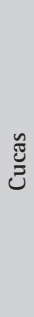 & 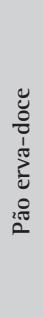 & $\begin{array}{l}\frac{\pi}{2} \\
\frac{\pi}{2} \\
\frac{\pi}{2} \\
\frac{\pi}{2} \\
\frac{\pi}{\pi} \\
\frac{\pi}{\pi} \\
\frac{20}{20} \\
2\end{array}$ & $\begin{array}{l}n \\
n \\
\tilde{\pi} \\
-\pi \\
\frac{\pi}{U} \\
0 \\
0 \\
0\end{array}$ & 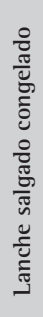 & 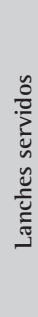 \\
\hline Linha light & 5,13 & & $x$ & $x$ & & $x$ & & & $x$ & & & \\
\hline Embalagem pronto pra comer & 5,63 & & $x$ & & & & & & & $x$ & & \\
\hline Pão quente durante todo o dia & 8,03 & $x$ & $x$ & & & & & $x$ & & & & \\
\hline Pães congelados & 4,29 & $x$ & $x$ & & $x$ & & & $x$ & & & & \\
\hline
\end{tabular}


uma das principais características do DEIN, que se apresenta como um modelo de suporte à inovação.

Entende-se que o fato da PAMP ser aplicável a todo tipo de projeto que a empresa venha a desenvolver pode ser vantajoso quanto à aceitação de futuros usuários. Isto é, com uma única ferramenta, a empresa consegue avaliar qualquer tipo de projeto, tanto através de análise puramente econômico-financeira, através do VPL e demais indicadores apresentados, quanto através de uma análise multicriterial que considera os atributos qualitativos importantes para a empresa/ projeto. Entretanto, o DEIN parece apresentar algumas vantagens em relação à PAMP para a análise de produtos. Uma delas é o fato discutido acima quanto aos vários fatores que influenciam o fluxo de caixa de um projeto, o que se não avaliado pode levar a erros graves de avaliação. Outra vantagem é o fato da ferramenta predefinir ações do tipo promover a inovação, manter como está ou aposentar o produto, orientando de forma clara o processo de tomada de decisão.

Outro item importante a ser considerado refere-se ao impacto de um produto no restante do portfólio. No DEIN, existe uma dimensão avaliando diretamente esse critério. Entretanto, na PAMP esse critério não está explícito. Logo, é necessário que o time atente para a possibilidade da receita de um produto atual variar em função da entrada de um outro produto. Um exemplo deste estudo de caso é o impacto dos pães congelados sobre o mesmo tipo de pão comercializado pronto atualmente. Existe a possibilidade de que a quantidade comercializada atualmente caia à medida que alguns clientes migrem para esse tipo de tecnologia. Nesse caso poderia ser associado um custo de perda de receita na PAMP, a fim de descontar essa receita que deixaria de entrar, ou atribuir um atributo negativo como, por exemplo, "perda de faturamento em outra linha”. No exemplo citado, o TDN preferiu não incluir essa perda, pois acredita que não haverá impactos negativos, uma vez que novos clientes serão atendidos a partir da introdução desses produtos no mix da empresa e existe uma tendência natural das vendas dos produtos em questão crescerem gradativamente.

Ao final da aplicação das ferramentas, o TDN foi questionado a respeito da adequabilidade das mesmas. Assim, o TDN concordou que as ferramentas contemplam todos os aspectos necessários para uma tomada de decisão e, por isso, poderiam ser utilizadas pela empresa. Entretanto, ficou claro que para isso algumas alterações precisam ser feitas para que o processo de obtenção dos dados de entrada seja facilitado. Foi relatado que alguns critérios avaliados com as ferramentas não têm sido levados em consideração nem mesmo informalmente no momento de tomar alguma decisão relacionada ao portfólio de produtos. Em relação a esse aspecto, observa-se que a aplicação das ferramentas pode contribuir para o aumento do formalismo e completude com que a empresa realiza a tomada de decisão sobre 0 portfólio. Com o tempo, certamente contribuiriam para o aumento da maturidade da empresa neste tocante.

A PAMP foi considerada um método detalhado e minucioso porém de grande valia, pois forçou a organização de informações da empresa que estavam documentadas formalmente ou não. Por outro lado, o uso de ferramentas de scoring models como o DEIN parece ser mais simples e de fácil aplicação, pois faria apenas a priorização dentre os vários projetos existentes, perdendo, contudo, a análise da viabilidade econômica de cada projeto.

Quando questionado sobre os atributos intangíveis, o gerente ressaltou que o objetivo principal de qualquer empresa é gerar lucro, e que, dessa forma, a lucratividade estaria em primeiro lugar de importância em todos os projetos apresentados, já que nenhum deles era de cunho mandatório.

\section{Conclusão}

Com base nas informações obtidas neste trabalho conclui-se que para um resultado confiável, a partir de ferramentas de GP, faz-se imprescindível a precisão e confiabilidade dos dados de entrada. Para isso é preciso que haja uma sistemática de documentação de dados do fluxo de caixa dos produtos existentes, a fim de facilitar as projeções do comportamento futuro de novos produtos. Conforme já citado pelas autoras das ferramentas aqui estudadas, a análise apurada da situação real da empresa permite que os dados de entrada sejam confiáveis e válidos para uso. Logo, pode-se dizer que os dados atuais servirão como facilitadores para a tomada de decisão futura. Em micro ou pequenas empresas como a que fez parte deste estudo, nas quais poucos participam do processo, esse pode ser um fator de viés, pois os dados podem não estar disponíveis e ser difícil o seu resgate e, consequentemente, eles podem ser estimados. Dessa forma, além de preparação técnica, o conhecimento documentado sobre os dados da empresa é fundamental, fazendo-se necessária a difusão de técnicas de gerenciamento de PDP e de projetos nesses tipos de empresas.

Cabe salientar que os resultados aqui apresentados são consequência de uma aplicação das ferramentas em estudo em uma empresa de pequeno porte, conforme já destacado. Isso permite concluir sobre o uso da ferramenta DEIN e PAMP em um ambiente específico, onde os dados disponíveis para análise foram gerados com a participação de poucas pessoas sem experiência 
e prática na temática de GP. Essa caracterísica pode ter influenciado nos resultados. Entretanto, destaca-se que ambas as ferramentas podem ser aplicadas em empresas de diferentes portes, o que diferencia uma organização de grande porte de uma de pequeno porte muitas vezes é exatamente sua base de dados e sua prática em relação à temática, bem como a maturidade em relação a seus processos de inovação.

Revendo o objetivo deste trabalho de comparar o DEIN e a PAMP quanto à aplicabilidade como ferramentas de análise de portfólio em uma empresa de pequeno porte, conclui-se que o objetivo principal foi cumprido. Contudo, a comparação das ferramentas mostra uma situação delicada, uma vez que vários fatores influenciam o fluxo de caixa, e, portanto, precisam ser feitas algumas adaptações para que a comparação dos resultados seja eficiente. É importante considerar que o DEIN foi desenvolvido para avaliar projetos de produtos, logo consegue avaliar todos esses fatores em harmonia. Entende-se que a PAMP possui características mais flexíveis, uma vez que pode ser aplicada a qualquer tipo de projeto ou negócio, pois não tem critérios de avaliação pré-definidos como o modelo DEIN, o que pode ser visto como uma vantagem de utilização. Nesse caso, devem ser observados aspectos importantes quanto à característica do projeto, conforme discutido neste trabalho. Apesar da ferramenta DEIN visar a definição do portfólio voltado para a inovação e a PAMP estar voltada para a análise econômico-financeira, o resultado obtido de cada uma não foi contraditório, pelo contrário, o ranking de produtos obtido foi semelhante, principalmente quando é considerada a situação dos produtos que compartilham os mesmos investimentos e, por isso, podem estar sofrendo viés na análise. Com isso pode-se dizer que neste trabalho o modelo de pontuação (scoring models) foi consistente com o método econômico. Além disso, as ferramentas parecem ter um caráter complementar no que diz respeito ao suporte à inovação dado pelo DEIN, conforme visto pelo número de produtos criados a partir da matriz de associação das ideias exequíveis aos produtos existentes. Por outro lado, a ferramenta PAMP confere um caráter mais quantitativo à tomada de decisão.

Face o cenário atual da empresa estudada, sugerem-se algumas ações que provavelmente podem servir como base de organização para as demais pequenas empresas: projetos de melhoria para o PDP que incluam a revisão do planejamento estratégico do negócio; gestão de projetos, a fim de estruturar a documentação; e GP devem ser implementados gradualmente para que a empresa consiga enfrentar a forte concorrência nesse mercado sempre altamente competitivo.
$\mathrm{Na}$ análise geral foi possível conhecer o efeito da aplicação de ferramentas de GP em um ambiente sem sistemática formalmente implementada para a GP do PDP. As ferramentas foram aplicadas com relativa facilidade na empresa de pequeno porte, porém uma sistemática deveria ser criada para sua aplicação ou adotada a dos próprios métodos DEIN e PAMP. Seria válido para trabalhos futuros a aplicação das mesmas ferramentas em empresas de médio ou grande porte e que tenham o PDP bem estruturado, a fim de traçar novamente um perfil comparativo e de análise dos resultados.

\section{Referências}

ASSOCIAÇÃO BRASILEIRA DAS INDÚSTRIAS DA ALIMENTAÇ̃̃ - ABIA. Disponível em: <http://www. abia.org.br/noticias.asp>. Acessado em: 20 abr. 2008.

ARCHER, N. P.; GHASEMZADEH, F. An integrated framework for project portfolio selection. International Journal of Project Management, v. 17, n. 4, p. 207-216, 1999. http://dx.doi.org/10.1016/S0263-7863(98)00032-5

BOSI, M. Estudo de Casos sobre a Gestão do Processo de Desenvolvimento de Produto na Indústria de Alimentos. In: CONGRESSO BRASILEIRO DE GESTÃO E DESENVOLVIMENTO DE PRODUTOS, 4., 2003, Gramado. Anais... Gramado, 2003.

BRASIL. Ministério da Saúde. Medicamentos. Agência Nacional de Vigilância Sanitária. Resolução RDC n² 275, de 21 de outubro de 2002. Dispõe sobre o Regulamento Técnico de Procedimentos Operacionais Padronizados aplicados aos Estabelecimentos Produtores/ Industrializadores de Alimentos e a Lista de Verificação das Boas Práticas de Fabricação em Estabelecimentos Produtores/Industrializadores de Alimentos. Diário Oficial da República Federativa do Brasil, Brasília, DF, 6 nov. 2002. Disponível em <http://www.anvisa.gov.br/elegis>. Acesso em: 20 abr. 2008.

BREALEY, R. A.; MYERS, S. C. Principles of Corporate Finance. 4. ed. New York: McGraw-Hill, 1991.

CASAROTTO FILHO, N.; KOPITTKE, B. H. Análise de Investimentos: matemática financeira, engenharia econômica, tomada de decisão e estratégia empresarial. 9. ed. São Paulo: Atlas, 2000.

COOPER, R. G.; EDGETT, S. J.; KLEINSCHMIDT, E. J. Portfolio Management for New Products. 2. ed. Persus Publishing, 2001.

CRAWFORD, M.; BENEDETO, C. A. New Products Management. 6. ed. Boston: McGraw Hill, 2000.

DANILEVICZ, A. Modelo para condução de decisões estratégias associadas ao gerenciamento da inovação em produtos. 2006. Tese (Doutorado em Engenharia de Produção)-Universidade Federal do Rio Grande do Sul, Porto Alegre, 2006.

DUTRA, C. C. Modelo Integrador para a Gestão de Portfólio de Projetos. 2007. Tese (Doutorado em Engenharia de Produção)-Universidade Federal do Rio Grande do Sul, Porto Alegre, 2007.

GIRO NEWS. A Inteligência no Ponto-de-Venda. 139. ed. Giro News, 2008. ano 12, p. 4-8. 
KAVADIAS, S. Project Portfólio Selection and Resource Allocation in New Product Development. 2001. Dissertação (Ph.D in Management)-INSEAD Fointanebleau, 2001.

KERZNER, H. Gestão de Projetos: as melhores práticas. 2. ed. Porto Alegre: Bookman, 2006.

KÖCHE, J. C. Fundamentos de Metodologia Científica: teoria da ciência e prática da pesquisa. 17. ed. Petrópolis: Vozes, 1997.

KOTLER, P. Administração de Marketing: Análise, Planejamento, Implementação e Controle. 5. ed. São Paulo: Atlas, 1998.

LOURENZANI, A. Gestão de Portfólio na Indústria de Alimentos: Um Estudo de Caso. In: ENCONTRO NACIONAL DE ENGENHARIA DE PRODUÇÃO - ENEGEP, 12.,2002, Curitiba. Anais... AEPRO, 2002.

MIZUTA, C. Y. Análise da Organização e da Gestão do Processo de Desenvolvimento de Produto na Indústria Alimentar - Estudo de Casos nos Segmentos de Biscoitos e Laticínios. 2000. Dissertação (Mestrado em Engenharia de Produção)-Universidade Federal de São Carlos, São Carlos, 2000.

MONTEIRO, A. Processo de Desenvolvimento de Produtos na Indústria de Biscoitos: Estudos de Caso em Fabricantes de Médio e Grande Porte, Fornecedores e Prestadores de Serviços. 2003. Dissertação (Mestrado em Engenharia de Produção)-Universidade Federal de São Carlos, São Carlos, 2003.
MOREIRA, R. Proposta de um Padrão Gerencial de Gestão de Portfólio de Novos Produtos para Indústrias Farmacêuticas Nacionais. 2008. Dissertação (Mestrado em Engenharia de Produção)-Universidade Federal de Minas Gerais, Belo Horizonte, 2008.

PATTERSON, M. L., FENOGL10, J. A. Leading Product Innovation: accelerating growth in a product-based business. New York: John Wiley \& Sons, 1999.

PROJECT MANAGEMENT INSTITUTE - PMI. Um Guia do Conjunto de Conhecimentos do Gerenciamento de Projetos (PMBoK). 3. ed. Project Management Institute, 2004.

PROJECT MANAGEMENT INSTITUTE - PMI. The Standard for Portfolio Management. Newtown Square, 2006.

ROZENFELD, $\mathrm{H}$. et al. Gestão de Desenvolvimento de Produtos: uma Referência para a Melhoria do Processo. São Paulo: Editora Saraiva, 2006.

SLACK, N.; CHAMBERS, S.; JOHNSTON, R. Administração da Produção. 2. ed. São Paulo: Atlas, 2002.

SMART, S. B.; MEGGINSON, W. L.; GITMAN, L. J. Corporate Finance. Mason: South-Western, 2004.

SOUZA, J. S. Proposta de uma Sistemática para Análise Multicriterial de Investimentos. 2008. Dissertação (Mestrado em Engenharia de Produção)-Universidade Federal do Rio Grande do Sul, Porto Alegre, 2008.

YIN, R. K. Estudo de Caso: Planejamento e Métodos. 3. ed. Porto Alegre: Bookman, 2005.

\title{
Comparative analysis of two Portfolio Management methods: a case study in the food industry
}

\begin{abstract}
Portfolio Management is the centralized management of one or more portfolios, which includes identifying, prioritizing, authorizing, managing and controlling projects, programs and related work to achieve specific strategic business objectives. There are different methods and tools in the literature that can be applied to portfolio management. The objective in this paper is to analyze the same portfolio using the DEIN and PAMP methods for comparison purposes. One of the tools is based on scoring models, while the other is based on economic-financial models. The case study was performed in a small food company where the feasibility of the two methods was evaluated. The results indicated that the methods can be applied complementarily and, although they present different basis, they resulted in a comparable product portfolio.
\end{abstract}

Keywords

Portfolio management. Scoring model. Economic-financial model. 